\title{
Effects of sediment compaction on macroinfauna in a protected coastal wetland in Taiwan
}

\author{
Chorng-Bin Hsu, Chang-Po Chen, Hwey-Lian Hsieh*
}

Biodiversity Research Center, Academia Sinica, Taipei 115, Taiwan, ROC

\begin{abstract}
We examined the effects of recreational trampling on wetland sediments, saltmarshes, and macroinfauna in November 2006 and April and July 2007. We used penetration resistance to measure sediment compaction at the Kaomei wetland, a protected intertidal coastal wetland harboring the largest tuberous bulrush marsh grass bed in Taiwan. We also examined the relationship of sediment compaction to visitor intensity and distribution of macroinfauna. Four compaction levels (low, medium-low, medium-high, and high) were identified using hierarchical cluster analysis. The spatial contour of sediment compaction was consistent with the level of visitor intensity, suggesting that human trampling is the main cause of sediment compaction in this wetland. Macroinfaunal abundance in low and medium-low compacted sediments was 4968 and 3376 ind. $\mathrm{m}^{-2}$, while no macroinfauna was recorded in highly consolidated sediments. Compared to those at medium-low compaction, taxon richness and community density at medium-high compaction were significantly reduced by 80.5 and $52.6 \%$, respectively. Polychaetes were more sensitive to sediment compaction than amphipods and bivalves, and could thus serve as a bioindicator of human trampling impact. A decrease in polychaete abundance may be attributed to their life history, which is controlled by substratum compaction. Our results showed that $25.7 \%$ of the study area was significantly compressed and that muddy vegetated areas were more vulnerable than sandy areas. We conclude that losses of macroinfauna and microhabitats are serious, and we propose management strategies to prevent further deterioration of this wetland.
\end{abstract}

KEY WORDS: Macroinfaunal community - Sediment compaction · Recreational trampling pressure · Coastal protected area management $\cdot$ Kaomei wetland

\section{INTRODUCTION}

Distribution of macroinfauna in coastal intertidal zones is mostly meditated by sediment properties, among which sediment firmness is a key factor (Rhoads 1974). Compacted sediment is defined as a reduction in sediment pore space, thus restricting air and water movement in the sediment and reducing the interstitial spaces habitable for infaunal organisms (Robertson \& Campanella 1983). This compaction is a signal of deterioration in sediment suitability and consequently of habitat degradation (Martínez \& Zinck 2004). Although sediment compaction has drawn great attention due to increasing anthropogenic activities in coastal areas (Sun \& Walsh 1998), its measures and effects on intertidal infaunal communities have not been well documented compared to terrestrial and agricultural systems (e.g. Gómez-Limón \& de Lucio 1995).

Penetration resistance (PR) of sediment has been developed as a fast and simple method to assess sediment compaction in the field. As PR increases, sediment compaction correspondingly increases. Changes in PR may be caused by internal and external factors. Internal factors are mostly related to sediment granulometry such as grain size, water content, and bulk density (Perumpral 1987). External factors include animal trampling (e.g. Greenwood et al. 1997), tillage 
practices (e.g. Thierfelder et al. 2005), vehicle traffic (Nevens \& Reheul 2003), and infaunal burrowing activities (e.g. Botto \& Iribarne 2000). In some wetlands and beaches, trampling by humans is a major disturbance (e.g. affecting ghost crab distribution and abundance, Steiner \& Leatherman 1981, Christoffers 1987; reducing shrimp abundance and seagrass biomass, Eckrich \& Holmquist 2000). Therefore, compaction measurement can serve as an indicator of impact intensity and recreational pressures (Belnap 1998, Sun \& Walsh 1998).

Intertidal salt marshes and sandflats are important feeding grounds for shorebirds, which are attracted to refuge and prey such as infaunal polychaetes and amphipods (Evans et al. 1998). In turn, birdwatchers are attracted by the birds, and recreational pressures become more intense in those wetlands with rich natural resources. Human trampling has been shown to cause reductions in vegetation biomass and macroand meiofaunal abundance in intertidal zones (e.g. Brown \& Taylor 1999, Casu et al. 2006). Faunal reductions occur because benthic organisms on the surfaces of trampled sediments experience increased desiccation, solar radiation, wave action, and predation (Schiel \& Taylor 1999). Such consequences are particularly severe for motile organisms like shrimps that are protected by seagrasses (Eckrich \& Holmquist 2000). More importantly, the effects of human trampling on sediment compaction can last for years if the compaction is not alleviated by natural forces such as wave reworking action. As a result, the resilience of benthic communities may be severely affected.

The Kaomei wetland, located in west-central Taiwan, is renowned for having the largest salt marsh of tuberous bulrush grass Bolboschoenus planiculmis in Taiwan and serves as an important bird staging area along the avian migratory routes in the West Pacific (Liao 2001). Although this area was designated as the Kaomei Wildlife Protected Area under Taiwan's 2004 Wildlife Conservation Act, the lack of available supporting data for proper management has resulted in visitors accessing the wetland so easily that the wetland's ecological function has been impaired, as indicated by the increasing destruction of vegetated areas.

Sediment consolidation from human trampling and the subsequent macroinfaunal responses have rarely been measured in coastal wetlands (for an exception, see Eckrich \& Holmquist 2000). To formulate guidelines for conserving the Kaomai wetland function, we need to understand the relationship between human trampling, sediment compaction, and adverse impact on benthic communities. This study focused on: (1) the relationship between trampling and sediment compaction, (2) the relationship between sediment compaction and changes in macroinfaunal distribution,
(3) the identification of indicative macroinfaunal taxa that best reflect changes with sediment compaction, and (4) the development of a wetland management and conservation strategy.

\section{MATERIALS AND METHODS}

Study area, sampling sites, and schedule. The Kaomei Wildlife Protected Area is located between the Tachia Creek estuary and Taichung Harbor in central Taiwan and covers approximately 701.3 ha. It consists of an estuarine area in the north and a coastal wetland in the south (Fig. 1). When Taichung Harbor was built in 1976, a groin led to the formation of the wetland by sand and mud accretion and by the growth of marsh grass Bolboschoenus planiculmis in the upper tidal zone. A $2 \mathrm{~km}$ long cobble pile, nearly perpendicular to the shoreline, was built to protect now-abandoned petroleum pipes that were buried underground.

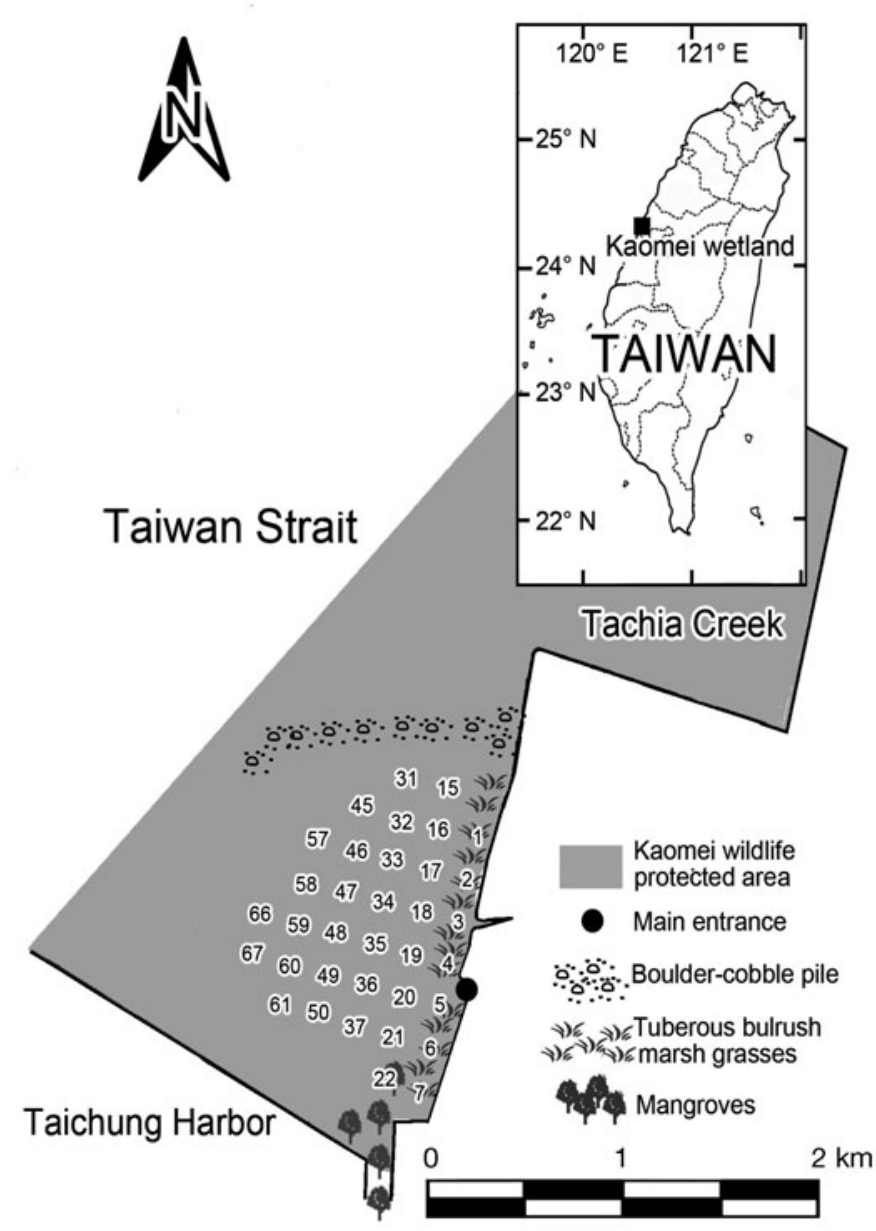

Fig. 1. Kaomei wetland, showing the locations of the 35 sampling sites and vegetation distribution. Visitors access the wetland mainly through the zone between Sites 4 and 5 . Site 7 is another popular entrance 
Perennial marsh grasses cover approximately 22.3 ha in the wetland area. Both above- and belowground biomass reach their peak from spring to summer (March to July). Underground portions include culm, tuber, rhizome, and root, and may grow $15 \mathrm{~cm}$ deep in the sediment. Different substrata including sand, mud, and marsh constitute diverse microhabitats in the wetland. The wetland area is mostly immersed during flood tides, while the intertidal flat may extend as wide as 2 to $3 \mathrm{~km}$.

A total of 35 sites on 6 transects parallel to the shoreline were designated for study (Fig. 1). The transect nearest to the shore was approximately $100 \mathrm{~m}$ from the dyke, and the distance between each transect was $200 \mathrm{~m}$. Between 2 and 8 sites were placed at $200 \mathrm{~m}$ intervals on each transect. PR, sediment, and benthic macroinfauna at each site were measured in November 2006 within $2 \mathrm{~h}$ of low tide. This sampling scheme allowed for minimizing the differences in water content among samples. Visitor intensity was quantified in April and July 2007.

Sediment compaction using PR. PR was measured with a $3 \mathrm{~cm}$ diameter, $30^{\circ}$ solid angle cone tip, handoperated, recording penetrometer (Penetrologger Set, Eijkelkamp Agrisearch Equipment). Sediment resistance to penetration per unit area is expressed as $10^{6} \mathrm{~N}$ $\mathrm{m}^{-2}=1 \mathrm{MPa}$ (e.g. Bengough et al. 2001). The PR readings were recorded from the sediment surface to $15 \mathrm{~cm}$ depth in $1 \mathrm{~cm}$ increments; accordingly, 16 readings were made in a 0 to $15 \mathrm{~cm}$ depth profile. Three PR readings were taken at each site and averaged to obtain the overall PR. Since greater sediment compaction results in greater resistance to penetration, the $\mathrm{PR}$ reading directly reflects the magnitude of sediment compaction. In most cases, we use the term 'sediment compaction' instead of 'PR' to describe the relationships between sediment compactness and benthic communities.

Trampling intensity using visitor counting. The intensity of human trampling that affected sediment compaction was examined by recording the numbers of visitors per site. We assumed that visitor number would be positively correlated with PR. Visitors were counted between 15:00 and 18:00 h on 1 weekend afternoon in both April and July 2007. This period was chosen because visitors preferred wading on the sand at sunset during low tides. Visitor counting was performed at sampling Sites 1 to 7,16 to 22,32 to 37 , and 45 to 50 (Fig. 1). A counting transect connecting adjacent paired sites in a north-south direction was established at each site, and the number of people who crossed this transect in $30 \mathrm{~s}$ was counted. This procedure was repeated 3 times at $30 \mathrm{~s}$ intervals. Overall, a total of 18 observations ( 3 per counting event $\times 6$ counting events) were made at each site.
Other sediment physical properties. Sediments were collected using an acrylic tube with a diameter of $2.6 \mathrm{~cm}$. During transport to the laboratory, all sediment samples were kept cool at approximately $4{ }^{\circ} \mathrm{C}$ while those for chlorophyll (chl) a content measurement were also kept in the dark. The top $3 \mathrm{~cm}$ of the sediment were sampled and analyzed for granulometry, water content, sediment $\mathrm{pH}$ and salinity, and total organic matter including total organic carbon (TOC) and total nitrogen (TN) content, and chl a samples were taken from the top $0.5 \mathrm{~cm}$. In the laboratory, samples for the measurement of TOC, TN, and chl a content were kept at $-80^{\circ} \mathrm{C}$ until cryo-dried.

Granulometry was determined following a protocol developed by Hsieh \& Chang (1991). Water content was the percent weight loss after oven-drying at $60^{\circ} \mathrm{C}$ to a constant weight. Sediment $\mathrm{pH}$ values were measured using a glass electrode $\mathrm{pH}$ meter in a 1:2 ratio of sediment to deionized water by weight (Chiu et al. 1999). Sediment salinity was determined using a refractometer on the strained interstitial water after the sediment was centrifuged. Sediment TOC and TN contents were analyzed using an element analyzer (Perkin-Elmer 2400 Series II CHNS/O) after sediments were treated by cryo-drying, passed through a $0.5 \mathrm{~mm}$ sieve to remove large animal pieces and plant debris, acidified with $1 \mathrm{~N} \mathrm{HCl}$ to remove inorganic carbons, and ground to fine powder. Chl a was extracted with $90 \%$ acetone and analyzed using a fluorometer (Model 10-AU, Turner Designs).

The depth of the oxygenated layer was measured in the field with a transparent acrylic corer (approximately $100 \mathrm{~cm}$ in length and $2 \mathrm{~cm}$ in diameter). A brown layer of sediment in a vertical profile indicates an oxygenic condition, whereas a black layer reflects a reduced condition due to the presence of sulfide compounds. A gray layer marks the transition between oxygenated and reduced conditions (Gray 1981). We used this simple method to understand how deep the sediment was aerated.

Macroinfaunal composition and density. Macroinfauna were sampled using a PVC corer with a diameter of $10 \mathrm{~cm}$ and treated following the procedures described by Hsieh (1995). The infaunal specimens that were retained on a $0.5 \mathrm{~mm}$ mesh sieve were identified to the lowest taxonomic level possible, and the numbers of individuals were counted. For those specimens for which the species could not be determined, major classes or orders were described. Taxon richness was calculated as the number of taxa per sample, and the densities of total macroinfauna and dominant taxa were expressed as ind. $\mathrm{m}^{-2}$.

Statistical analyses. Since the values of PR at 16 different sediment depths showed obvious multicollinearity, information provided by separate univari- 
ate analyses at each depth was redundant. To understand whether mean PR (MPR) values could be used to represent the sediment compaction at each site despite the fact that PR increased with depth, a principal component analysis (PCA) was conducted. After the main components of $\mathrm{PR}$ values recorded in the 0 to $15 \mathrm{~cm}$ depth profile were determined, linear regression was used to examine the relationships between MPR values and the main components. The results of PCA and regression analysis showed that the MPR was significantly related to the first principal component (linear regression, $\left.\mathrm{r}^{2}=0.66, \mathrm{p}<0.001\right)$. Therefore, MPR was used to represent sediment compaction at each site.

To classify sites with similar compaction patterns, hierarchical cluster analysis was conducted for all sampling sites using all vertical PR readings. Differences in mean taxon richness and the densities of total macroinfauna and dominant taxa among different clusters of sediment compaction were analyzed using nonparametric 1-way analysis of variance (ANOVA) with a Kruskal-Wallis test. Following a significant ANOVA, Dunn's multiple comparison procedure was performed to test differences between means (Zar 1996). The relationships between sediment physical properties and the densities of macroinfauna including amphipods, annelids (polychaetes and oligochaetes), bivalves, and brachyurans were determined using canonical correlation analysis (Digby \& Kempton 1987). The relation- ships of other sediment physical properties with MPR levels were also plotted for saltmarsh and non-saltmarsh sites. Significance levels were 0.05.

All statistical analyses including PCA were conducted using the software package SAS 9.1 (SAS Institute 2003). Hierarchical analysis was performed using the PRIMER v.5 computer software (Clarke \& Gorley 2001).

\section{RESULTS}

\section{Vertical profiles and spatial distribution patterns}

Hierarchical cluster analysis classified the 35 sampling sites into 4 clusters with different compaction levels: low, medium-low, medium-high, and high (Fig. 2). MPR values were 0.30, 0.57, 0.82, and $1.45 \mathrm{MPa}$, respectively. In addition, vertical profiles indicated that the sediment compression increased with depth (Fig. 3). The spatial contour of MPR showed that the highest compaction occurred at Site 19 with a value of $1.75 \mathrm{MPa}$, followed by Site 7 with a value of $1.15 \mathrm{MPa}$ (Fig. 4) and from these 2 sites, the MPR gradually decreased to the peripheral areas. The 4 compaction levels based on the clustering analysis were consistent with that drawn from the MPR contour (Fig. 4).

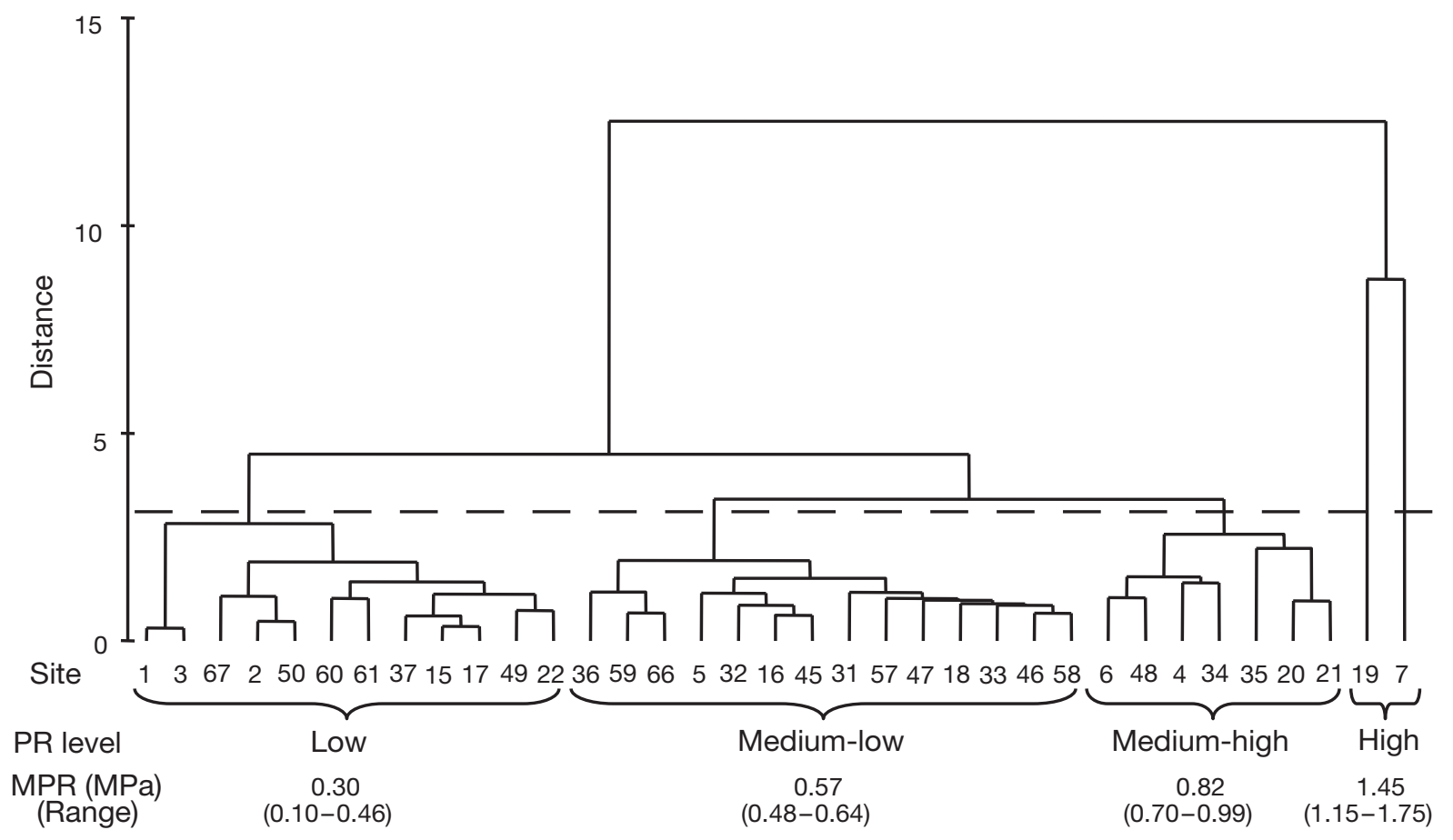

Fig. 2. Sediment compaction from all 35 sampling sites based on the penetration resistances (PR) recorded at each depth throughout the 0 to $15 \mathrm{~cm}$ depth profile using hierarchical clustering. Four clusters are identified, and below each cluster, the mean valueof penetration resistance (MPR) is given on an MPa scale with ranges in parentheses. Dashed line: cut off distance value for distinguishing the clusters 


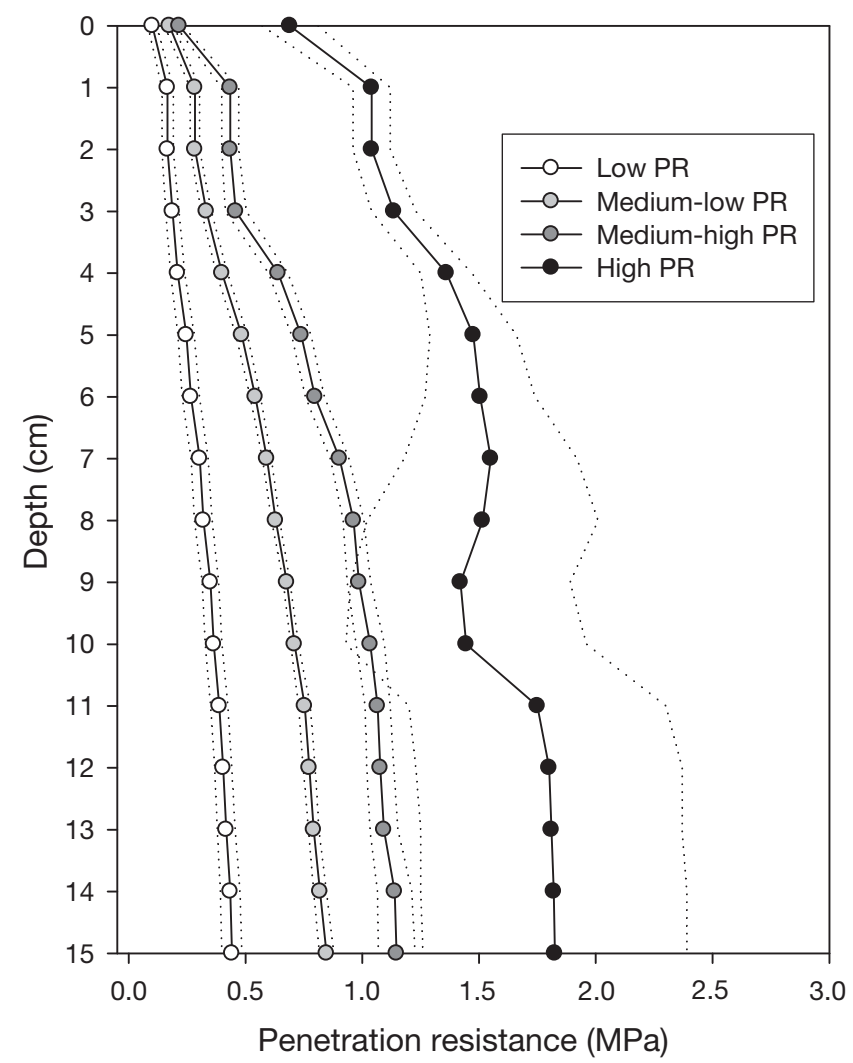

Fig. 3. Vertical profiles of the 4 sediment compaction clusters. For each cluster, the profile is represented by the mean values of penetration resistance (solid line) and standard errors (dotted lines) at each depth

\section{Spatial distribution of visitors}

More people visited Kaomei wetland in July than in April, but spatial distribution patterns of visitations were similar, with 2 areas of concentration (Fig. 5). The spatial contour of visitor intensity was consistent with that of PR, revealing that trampling was closely correlated with sediment compaction (Figs. 4 \& 5). Areas covered by tuberous bulrush grasses, such as Sites 1,2 , and 3, had relatively low $\mathrm{PR}$, reflecting that their underground roots and rhizomes did not contribute to the substratum compaction.

\section{Macroinfaunal distribution and sediment compaction}

A total of 927 organisms from 23 taxa were collected. Amphipoda, Polychaeta, and Bivalvia accounted for $86.84 \%, 8.74 \%$, and $2.48 \%$ of the total abundance of the macroinfauna, and other taxa accounted for less than $2 \%$ of total abundance (Table 1). Amphipods were dominant at sites with sediment compaction from low to medium-high levels, whereas, polychaetes were more common at sites with low and medium-low compaction. The bivalve Mactra veneriformis occurred more frequently in areas with medium-low compaction (Table 1). Taxon richness of macroinfauna per sample was similar at low and medium-low compaction, but significantly lower at medium-high compaction $(\mathrm{p}=$ 0.0003; Fig. 6). Total density of macroinfauna decreased from low to high compaction ( $p=0.027$; Fig.6).
Fig. 4. Spatial contours of mean values of penetration resistance (MPR). The 4 spatial groupings of sediment compaction are based on clustering analyses used in Fig. 2

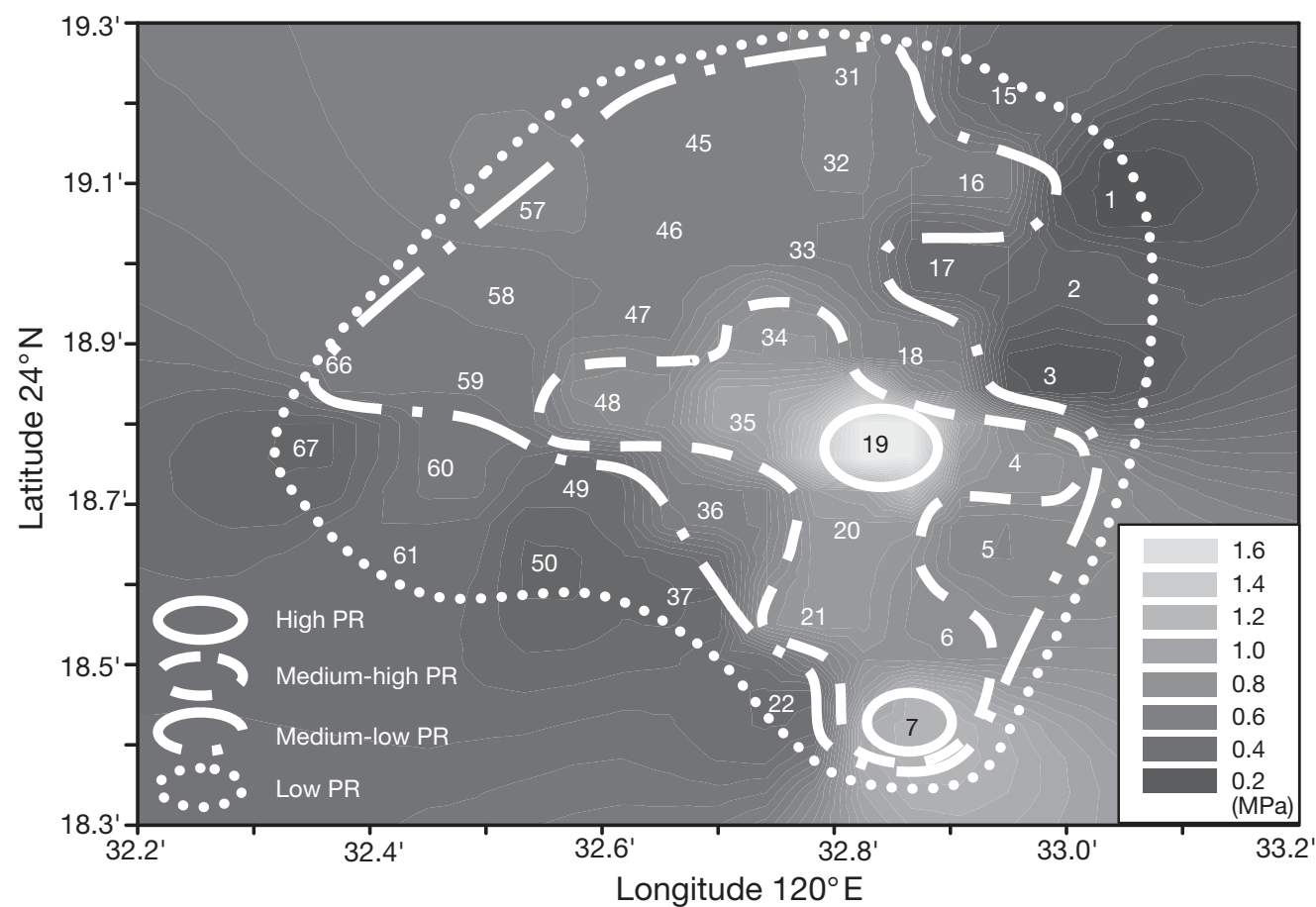




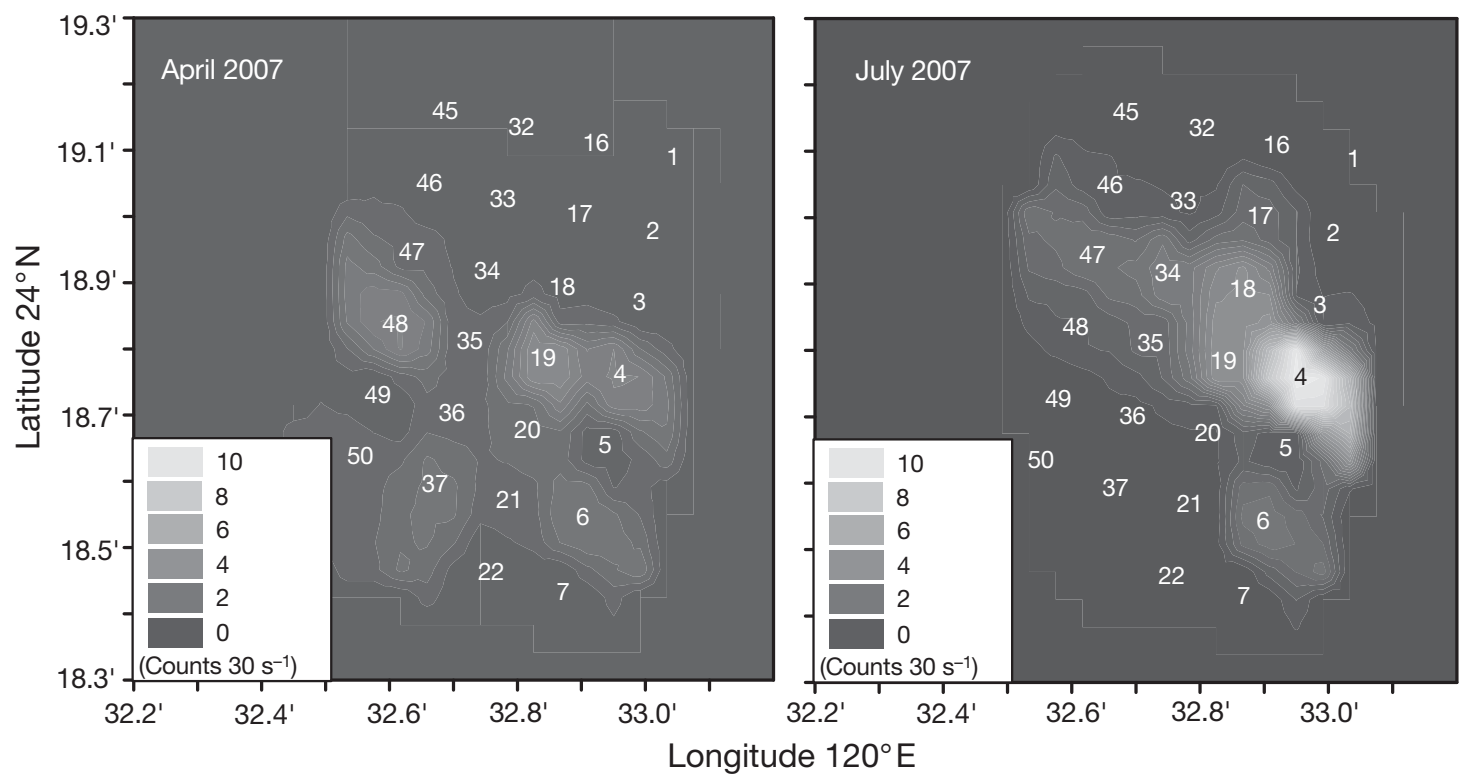

Fig. 5. Spatial contours of visitor counts recorded on weekends in April and July 2007

Table 1. Density (number of individuals $\mathrm{m}^{-2}$ ) of each macroinfaunal taxon and their relative abundance (\%) to the total abundance of the benthic community collected at each of the 4 sediment compaction levels in the Kaomei wetland. Sediment compaction levels, L: low; M-L: medium-low; M-H: medium-high; H: high. Density is shown in mean $\pm \mathrm{SE}$

\begin{tabular}{|c|c|c|c|c|c|}
\hline \multirow[t]{2}{*}{ Taxon } & \multicolumn{4}{|c|}{ - Mean density at each sediment compaction level _ـ } & \multirow{2}{*}{$\begin{array}{l}\text { Relative abundance } \\
\qquad(\%)\end{array}$} \\
\hline & $\begin{array}{c}\mathrm{L} \\
(\mathrm{n}=12)\end{array}$ & $\begin{array}{c}\mathrm{M}-\mathrm{L} \\
(\mathrm{n}=14)\end{array}$ & $\begin{array}{c}\mathrm{M}-\mathrm{H} \\
(\mathrm{n}=7)\end{array}$ & $\begin{array}{c}\mathrm{H} \\
(\mathrm{n}=2)\end{array}$ & \\
\hline \multicolumn{6}{|l|}{ Mollusca } \\
\hline Bivalvia & & & & & 2.48 \\
\hline Glauconome chinensis & 0 & $9.1 \pm 9.1$ & 0 & 0 & 0.11 \\
\hline Laternula anatine & 0 & $18.2 \pm 12.4$ & 0 & 0 & 0.22 \\
\hline Mactra veneriformis & $10.6 \pm 10.6$ & $118.3 \pm 63.3$ & $18.2 \pm 18.2$ & 0 & 1.62 \\
\hline Sanguinolaria diphos & $10.6 \pm 10.6$ & 0 & 0 & 0 & 0.11 \\
\hline Moerella rutila & 0 & $36.4 \pm 16.0$ & 0 & 0 & 0.43 \\
\hline \multicolumn{6}{|l|}{ Annelida } \\
\hline Polychaeta & & & & & 8.74 \\
\hline Capitella spI & $42.5 \pm 32.6$ & 0 & 0 & 0 & 0.43 \\
\hline Mediomastus (?) sp. & $222.9 \pm 189.6$ & $27.3 \pm 27.3$ & 0 & 0 & 2.59 \\
\hline Glycera subaenae & $116.8 \pm 63.6$ & $118.3 \pm 43.2$ & 0 & 0 & 2.59 \\
\hline Namalycastis abiuma & $21.2 \pm 21.2$ & 0 & 0 & 0 & 0.22 \\
\hline Armandia sp. & 0 & $36.4 \pm 28.1$ & 0 & 0 & 0.43 \\
\hline Scoloplos marsupialis & $10.6 \pm 10.6$ & $18.2 \pm 18.2$ & 0 & 0 & 0.32 \\
\hline Laonome albicingillum & 0 & $18.2 \pm 12.4$ & 0 & 0 & 0.22 \\
\hline Prionospio paradisea & $21.2 \pm 21.2$ & $72.8 \pm 34.6$ & 0 & 0 & 1.08 \\
\hline Pseudopolydora gigeriosa & 0 & $9.1 \pm 9.1$ & 0 & 0 & 0.11 \\
\hline Scolelepis lamellicincta & $31.9 \pm 31.9$ & $36.4 \pm 20.8$ & 0 & 0 & 0.76 \\
\hline Oligochaeta & $74.3 \pm 55.4$ & 0 & 0 & 0 & 0.76 \\
\hline Nemertea & $10.6 \pm 10.6$ & 0 & 0 & 0 & 0.11 \\
\hline Sipuncula & $21.2 \pm 14.3$ & 0 & 0 & 0 & 0.22 \\
\hline \multicolumn{6}{|l|}{ Arthropoda } \\
\hline Amphipoda & $4320.6 \pm 2447.2$ & $2838.9 \pm 2666.0$ & $1565.1 \pm 1292.5$ & 0 & 86.84 \\
\hline Brachyura & & & & & 0.54 \\
\hline Metaplax elegans & $21.2 \pm 21.2$ & $9.1 \pm 9.1$ & $18.2 \pm 18.2$ & 0 & 0.43 \\
\hline Xanthidae & 0 & $9.1 \pm 9.1$ & 0 & 0 & 0.11 \\
\hline Insecta & & & & & 0.33 \\
\hline Chironomini & $21.2 \pm 21.2$ & 0 & 0 & 0 & 0.22 \\
\hline Dolichopodidae & $10.6 \pm 10.6$ & 0 & 0 & 0 & 0.11 \\
\hline Total & $4968.2 \pm 2390.6$ & $3375.8 \pm 2654.7$ & $1601.5 \pm 1285.3$ & 0 & 100.0 \\
\hline
\end{tabular}




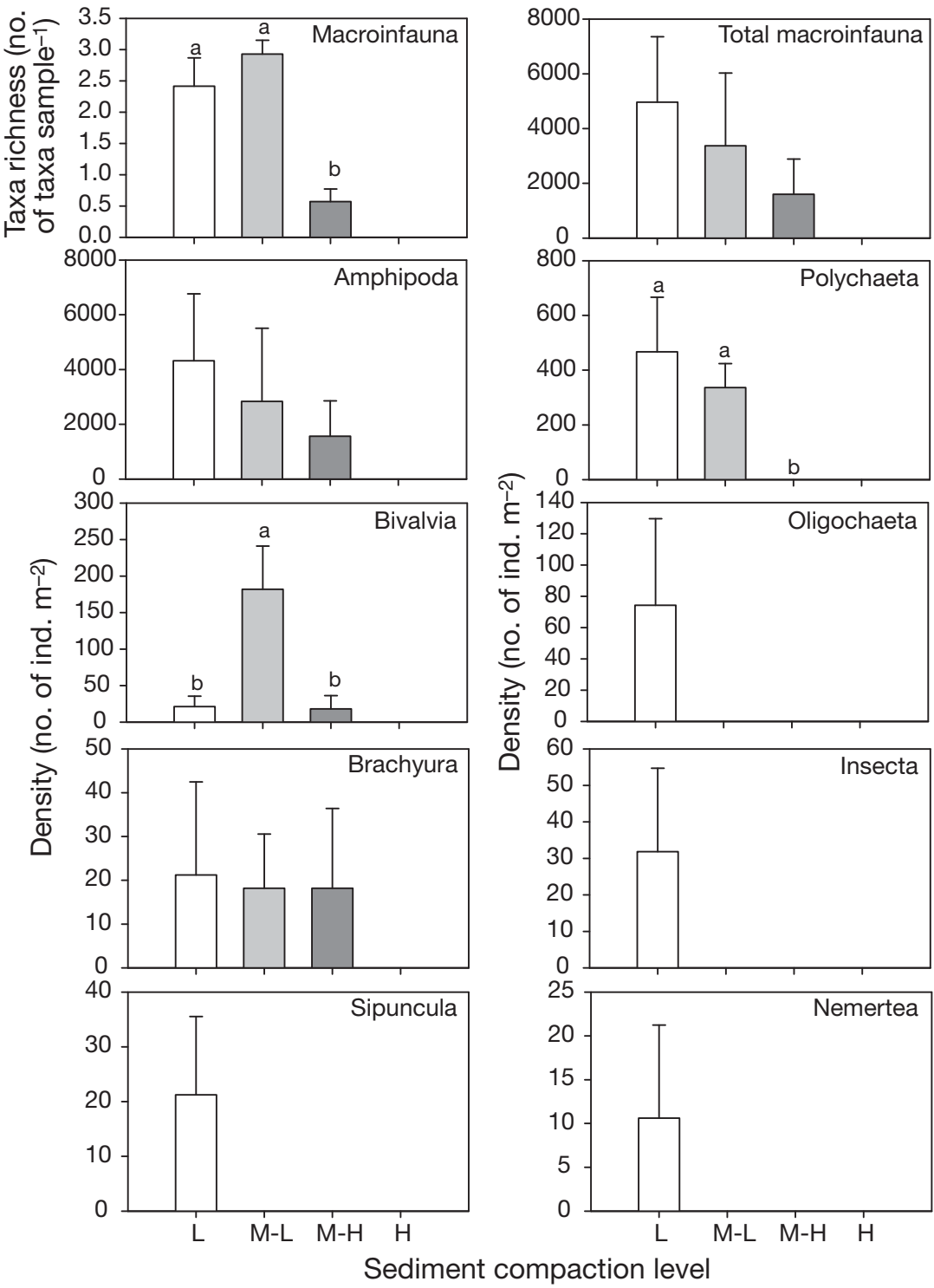

Fig. 6. Changes in mean taxon richness sample ${ }^{-1}$ (top left), density of total benthic macroinfauna (top right) (mean $\pm \mathrm{SE}$ ), and densities of each taxon (mean $\pm \mathrm{SE}$ ) at the 4 sediment compaction levels: L: low; M-L: medium-low; M-H: medium-high; $\mathrm{H}$ : high. Levels marked with different letters indicate significant differences

Overall, in areas with medium-high and high compaction $(>0.70 \mathrm{MPa})$, taxon richness dropped by $80.5 \%$, from 2.93 taxa sample ${ }^{-1}$ at medium-low to 0.57 at medium-high compaction, and total density of macroinfauna decreased by $52.6 \%$ (Table 1, Fig. 6). Densities of amphipods and polychaetes decreased from low to high compaction. This pattern was similar to that of total macroinfauna despite insignificant site differences (PR level differences) in amphipods. The highest abundance of bivalves occurred at sites with medium-low compaction, whereas the highest abundance of brachyurans was found at sites with low to medium-high compaction. The remaining rare taxa were all found at sites with low compaction (Table 1, Fig. 6).

\section{Sediment compaction and other sediment physical properties}

No clear relationships were found between sediment compaction and most of the other sediment physical properties at saltmarsh and non-saltmarsh sites, except for chl a content (Fig. 7), which decreased as compaction increased (Spearman's $r=$ $-0.74, p=0.0001)$. In saltmarsh areas, however, the relationships became clearer, and PR was inversely correlated with silt/clay content $(\mathrm{r}=-0.86$, $\mathrm{p}=0.01)$ and TOC $(\mathrm{r}=-0.79, \mathrm{p}=0.04$; Fig. 7).

\section{Macroinfaunal density, sediment compaction, and other sediment physical properties}

The first 2 axes in the canonical correlations represented $66.8 \%$ and $23.6 \%$ of variance. Canonical correlation coefficients were both significant $\left(\mathrm{r}_{1}=0.76, \mathrm{p}=0.0003 ; \mathrm{r}_{2}=0.58, \mathrm{p}=\right.$ 0.04). The first axis of canonical variables suggests that TOC and grain size were the main factors affecting the distribution of macroinfauna, and the second axis suggests the importance of sediment compaction (as PR measures, Fig. 8). The density of brachyurans was positively correlated with TOC and silt/clay content, but negatively correlated with grain size (Fig. 8). Densities of the annelids (mainly polychaetes) were greater at sites with coarser grain size and lower sediment compaction. Comparatively, the densities of branchyurans, bivalves, and amphipods did not exhibit a clear relationship with compaction (Fig. 8).

\section{DISCUSSION}

\section{Effects of human trampling on sediment compaction}

We quantified the level of substratum compression that macroinfauna can withstand. In the Kaomei wetland, human-trampled areas having a sediment com- 

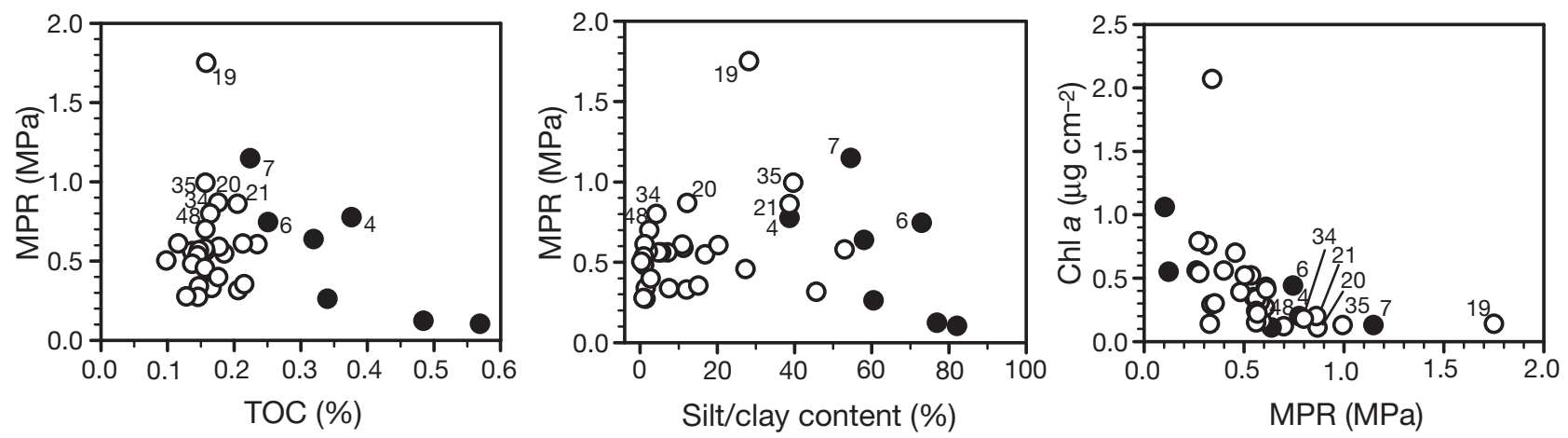

Fig. 7. Relationships between mean penetration resistance (MPR) and other sediment physical properties in saltmarsh (•) and non-saltmarsh (O) sites. Numbers inside each plot indicate the sites with medium-high and high sediment compaction. TOC: total organic carbon content

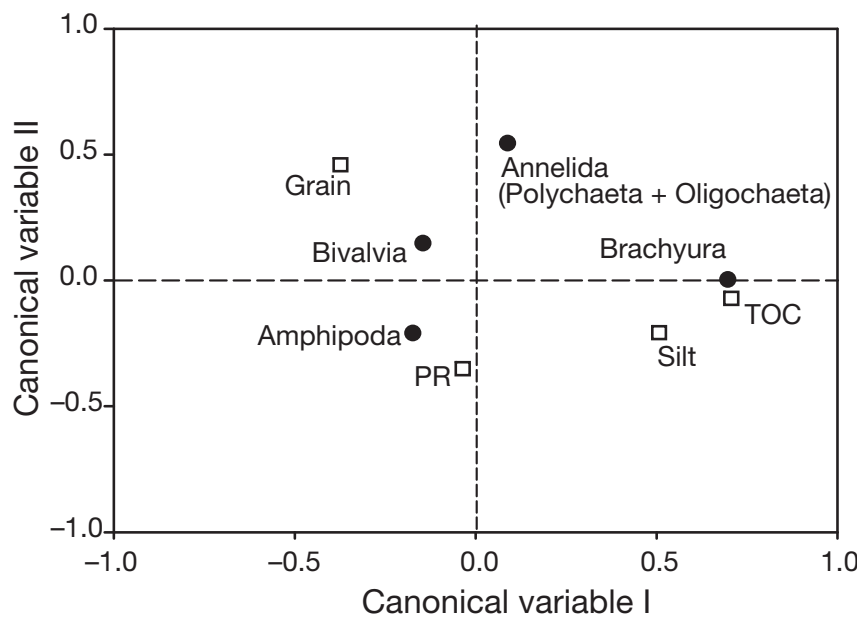

Fig. 8. Relationships between the densities of benthic macroinfauna $(\bullet)$ and sediment physical properties $(\square)$ on the first 2 canonical variables using canonical correlation analysis. Grain: median grain size; PR: penetration resistance value; silt: silt/clay content; TOC: total organic carbon content

paction greater than $0.70 \mathrm{MPa}$ suffered biodiversity losses whereby taxon richness decreased over $80 \%$ and abundance diminished over $52 \%$. Factors other than human trampling, such as increases in pneumatophore density in mangroves, might also lead to sediment compaction (Morrisey et al. 2003). We ruled out this possibility for the Kaomei wetland because areas densely populated with marsh grass (Sites 1, 2, and 3) exhibited relatively low sediment compaction. Our results demonstrate that human visitation, rather than the underground roots or rhizomes of the marsh grasses, accounts for wetland substratum firmness.

The degree of sediment compaction correlates with several sediment physical properties. In coastal environments, previous studies indicated that sediment PR was inversely dependent on water content and changed during the tidal cycle (Perkins 1958, Perum- pral 1987). Spivey et al. (1986) reported that sandy soils had a broader range of probe resistances while silt and clay soil had a narrower range. From these observations, sediment compaction appeared to be negatively correlated with silt, clay, and organic contents, and positively correlated with sand content. By contrast, in the Kaomei wetland, no trend was found between sediment compaction and other sediment physical properties when vegetated and non-vegetated areas were combined for analyses.

Nevertheless, when non-saltmarsh areas were compared to saltmarshes, negative correlations in sediment compaction with silt/clay content and organic carbon content were observed (see Fig. 7). This discrepancy can be explained by interactions of sediment properties and patterns in trampling. The saltmarsh sediments are muddier with higher silt/clay content and organic matter content than the non-saltmarsh sediments (see Fig. 7). Marsh sediments become finer because siltation is gradually enhanced after bulrush colonization. In addition, visitors' wading trails tend to form at the edges of the saltmarsh area as visitors avoid getting stuck inside the muddy marshes (Sites 4, 6, and 7 are sparsely vegetated due to trampling; authors' pers. obs.). As a result, the sediment in the border area of the saltmarsh is gradually consolidated. These data also suggest that human trampling could alter a muddy substratum more drastically than a sandy substratum, corroborating earlier studies (e.g. Eckrich \& Holmquist 2000). Sediment chl a content decreases as sediment compaction increases in both environments, due to loss of surface area for attachment and growth.

\section{Vertical profiles of sediment compaction}

In terrestrial ecosystems, sediment compaction caused by sheep trampling was limited to the top $5 \mathrm{~cm}$ in dry soils (Greenwood et al. 1997), or up to $15 \mathrm{~cm}$ in 
wet soils (Mead \& Chan 1992). Cattle affected both depth and degree of sediment compaction, which increased with duration of cattle grazing (e.g. the PR reached a peak of $5 \mathrm{MPa}$ at $15 \mathrm{~cm}$ in $12 \mathrm{yr}$ versus 6.6 MPa at $25 \mathrm{~cm}$ in $50 \mathrm{yr}$, Bachmann et al. 2006). In our wetland study, the surface $3 \mathrm{~cm}$ layer of substratum seemed to be the least compacted. However, the firmness increased more obviously at depths of 3 to $5 \mathrm{~cm}$, especially at those sites with medium-high and high compaction, suggesting that the effect of visitors' trampling in this wetland is highest in this layer (see Fig. 3). We speculate that the local wave-induced substratum reworking, such as that produced by the daily tidal cycle, is limited to the surface layers of a few $\mathrm{cm}$. Consequently, recovery of sediment compaction to its unaffected status would require larger wave actions or human restoration efforts.

\section{Changes of macroinfauna with sediment compaction}

In the Kaomei wetland, amphipods and the highly motile grapsid brachyuran Metraplax elegans appear not to be affected by sediment compaction. By contrast, the bivalve Mactra veneriformis appears to prefer medium-low compacted substratum. This pattern infers that the bivalve exhibits similar responses to the low or high sediment compaction, but the 2 underlying mechanisms are different. This bivalve is a small suspension-feeding sessile infaunal species (approximately $1 \mathrm{~cm}$ in width collected in this study). Sites with high compaction, thus reflecting firmer substrata, may discourage a small sized burrower, because firmness would increase the energy cost of burrowing activities (Brown \& Trueman 1991). Sites with low compaction (softer substrata, e.g. Sites 1, 2, and 3) may not favor a suspension feeder due to slow currents, which bring fewer food particles into the water column (Jumars \& Nowell 1984). Softer substrata (e.g. Sites 49, 50, 60, 61, and 67) may also not provide enough support for burrows, which would hinder $M$. veneriformis habitation.

Sessile and semi-sessile infaunal polychaetes, a major group of benthos in soft-bottom habitats, appear to be more vulnerable to sediment compaction than other groups. Infaunal polychaetes ingest sediment when feeding, manipulate sediment when constructing tubes, and displace sediment when burrowing (Rhoads 1974). Firmness of sediments has been recognized as an important feature in mediating such adaptations (Rhoads 1974), and compressed sediment is evolutionarily unsuitable for infaunal polychaetes in the Kaomei wetland. We have seen significant reductions in the density of polychaetes at medium-high and high compaction sites and suggest that the presence of polychaetes is indicative of non-compacted sediments and may be used as a management indicator. Another example of acceptable visitation pressure thresholds was also based on species-specific vulnerability instead of the whole community (Gallet \& Roze 2001).

Since the taxon richness and total densities of macroinfauna and polychaetes in the Kaomei wetland decreased significantly at sediment compaction greater than $0.70 \mathrm{MPa}$, we suggest that areas exceeding this threshold can be classified as impacted. Of 35 sites, 9 exhibited sediment compaction ranging from 0.70 to 1.75 MPa, demonstrating that $25.7 \%$ of the study area is unfavorable habitat for macroinfauna.

\section{Recommendations for wetland conservation management}

Sediment compactness in the study area was consistent with visitation intensity and not with any other measured sediment attributes (see Fig. 7), and crowds of visitors have been repeatedly observed in the protected Kaomei wetland. We therefore recommend 5 strategic management guidelines for the Kaomei wetland as follows:

(1) Limit the number of tourists allowed in the protected wetland to lessen sediment compaction. Limitations might be achieved by (a) limiting access to a specific time of year, (b) limiting the number of people who can enter the area on a daily basis, and (c) charging an admission fee that is high enough to discourage casual visits, and using the fee to fund restoration work. If combined with communication and education about preserving this important wetland, tourists will perceive limited access as a privilege and a way to participate in preservation, rather than as a loss of freedom.

(2) Designate those areas that accommodate diverse microhabitats and are not yet affected by anthropogenic activities as core protected zones. This zonation should include tuberous bulrush marshes, mud, and sand flats. The range approximately covers the sites from 1 to 3,15 to 17,31 to 33,45 to 47 , and 57 to 59 , and 66 , an area located north of the main wading trail that is currently used heavily by visitors.

(3) Develop alternative trails for visitor use when measures of the sediment $\mathrm{PR}$ reach threshold levels. When the PR values on a given trail approach $0.70 \mathrm{MPa}$, that trail should be closed until recovery through natural processes of tidal and wave actions occurs.

(4) Implement a proper restoration plan as soon as practical for seriously compacted areas as with medium-high compaction before irreversible injury occurs. Plowing can be practiced on the main trail exemplified at Sites 4 and 6, 20 and 21, 34 and 35, and 48 . 
(5) Develop and implement effective monitoring programs to measure ecological impacts and recovery, schedule path rotation, survey public usage and compliance with path marking, and communicate results to management and the public. Scientific assessments, communication/inspiration, and practice are fundamental in effective monitoring programs and public education.

\section{CONCLUSIONS}

Formation of a management policy is urgently needed for this protected area. The measurement of PR is a useful tool for assessing trampling impact and regulating recreational pressure. To conserve the microhabitats and biodiversity of the Kaomei wetland, the threshold of acceptable sediment compaction appears to fall below $0.70 \mathrm{MPa}$, and polychaetes appear to be the best bioindicator taxon. Further studies to determine the best methods to restore compacted sediments will be valuable for the conservation of this wetland.

Acknowledgements. We sincerely thank Drs. D. Sheehy and S. Vik, Aquabio Inc., USA, for reading an earlier draft of the manuscript. We are grateful to anonymous reviewers for their constructive criticism. This study was supported by the National Science Council of Taiwan, ROC, with grant NSC 95-2621-B-001-012. The study complies with the current laws of Taiwan.

\section{LITERATURE CITED}

Bachmann J, Contreras K, Hartge KH, MacDonald R (2006) Comparison of soil strength data obtained in situ with penetrometer and with vane shear test. Soil Tillage Res 87: $112-118$

Belnap J (1998) Choosing indicators of natural resource condition: a case study in Arches National Park, Utah, USA. Environ Manage 22:635-642

Bengough AG, Campbell DJ, O'Sullivan MF (2001) Penetrometer techniques in relation to soil compaction and root growth. In: Smith KA, Mullinsed CE (eds) Soil and environmental analysis: physical methods, 2nd edn. Marcel Dekker, New York, NY, p 377-403

Botto F, Iribarne O (2000) Contrasting effects of two burrowing crabs (Chasmagnathus granulata and Uca uruguayensis) on sediment composition and transport in estuarine environments. Estuar Coast Shelf Sci 51:141-151

Brown PJ, Taylor RB (1999) Effects of trampling by humans on animals inhabiting coralline algal turf in the rocky intertidal. J Exp Mar Biol Ecol 235:45-53

Brown AC, Trueman ER (1991) Burrowing of sandy-beach molluscs in relation to penetrability of the substratum. J Molluscan Stud 57:134-136

> Casu D, Ceccherelli G, Castelli A (2006) Immediate effects of experimental human trampling on mid-upper intertidal benthic invertebrates at the Asinara Island MPA (NW Mediterranean). Hydrobiologia 555:271-279

Chiu CY, Lai SY, Wang CJ, Lin YM (1999) Transfer of ${ }^{137} \mathrm{Cs}$ from soil to plants in a wet montane forest in subtropical Taiwan. J Radioanal Nucl Chem 239:511-515

Christoffers EW (1987) Ecology of the ghost crab Ocypode quadrata (Fabricius) on Assateague Island, Maryland, and the impacts of various human uses of the beach on their distribution and abundance. PhD dissertation, Michigan State University, East Lansing, MI

Clarke KR, Gorley RN (2001) PRIMER v5: user manual/tutorial. PRIMER-E, Plymouth

Digby PGN, Kempton RA (1987) Multivariate analysis of ecological communities. Chapman and Hall, London

Eckrich CE, Holmquist JG (2000) Trampling in a seagrass assemblage: direct effects, response of associated fauna, and the role of substrate characteristics. Mar Ecol Prog Ser 201:199-209

Evans PR, Ward RM, Bone M, Leakey M (1998) Creation of temperate-climate intertidal mudflats: factors affecting colonization and use by benthic invertebrates and their bird predators. Mar Pollut Bull 37:8-12

> Gallet S, Roze F (2001) Resistance of Atlantic heathlands to trampling in Brittany (France): influence of vegetation type, season and weather conditions. Biol Conserv 97: $189-198$

Gómez-Limón FJ, de Lucio JV (1995) Recreational activities and loss of diversity in grasslands in Alta Manzanares Natural Park, Spain. Biol Conserv 74:99-105

Gray J (1981) The ecology of marine sediments. Cambridge University Press, Cambridge

> Greenwood KL, MacLeod DA, Hutchinson KJ (1997) Longterm stocking rate effects on soil physical properties. Aust J Exp Agric 37:413-419

> Hsieh HL (1995) Spatial and temporal patterns of polychaete communities in a subtropical mangrove swamp: influence of sediment and microhabitat. Mar Ecol Prog Ser 127: 157-167

Hsieh HL, Chang KH (1991) Habitat characteristics and occurrence of the spionid Pseudopolydora sp. on the tubecaps of the onuphid Diopatra biolobata (Polychaeta: Spionidae, Onuphidae). Bull Inst Zool Acad Sin 30:331-339

Jumars PA, Nowell ARM (1984) Fluid and sediment dynamic effects on marine benthic community structure. Am Zool 24:45-55

Liao S (2001) Important bird areas in Taiwan. Wild Bird Federation Taiwan, Taipei

Martínez LJ, Zinck JA (2004) Temporal variation of soil compaction and deterioration of soil quality in pasture areas of Colombian Amazonia. Soil Tillage Res 75:3-17

> Mead JA, Chan KY (1992) Cultivation techniques and grazing affect surface structure of an Australian hardsetting soil. Soil Tillage Res 25:217-230

Morrisey DJ, Skilleter GA, Ellis JI, Burns BR, Kemp CE, Burt K (2003) Differences in benthic fauna and sediment among mangrove (Avicennia marina var. australasica) stands of different ages in New Zealand. Estuar Coast Shelf Sci 56:581-592

> Nevens F, Reheul D (2003) The consequences of wheel-induced soil compaction and subsoiling for silage maize on a sandy loam soil in Belgium. Soil Tillage Res 70:175-184

> Perkins EJ (1958) The hardness of the soil of the shore at Whitstable, Kent. J Ecol 46:71-81

Perumpral JV (1987) Cone penetrometer application-a review. Trans ASAE (Am Soc Agric Eng) 30:939-944

Rhoads DC (1974) Organism-sediment relations on the muddy sea floor. Oceanogr Mar Biol Annu Rev 12: 263-300

> Robertson PK, Campanella RG (1983) Interpretation of cone penetration tests. Part I: Sand. Can Geotech J 20:718-733 
SAS Institute (2003). SAS user's guide: statistics, release 9.1. SAS Institute, Cary, NC

Schiel DR, Taylor DI (1999) Effects of trampling on a rocky intertidal algal assemblage in southern New Zealand. J Exp Mar Biol Ecol 235:213-235

Spivey LD Jr, Busscher WJ, Campbell RB (1986) The effect of texture on strength of southeastern coastal plain soils. Soil Tillage Res 6:351-363

Steiner AJ, Leatherman SP (1981) Recreational impacts on the distribution of ghost crabs Ocypode quadrata Fab. Biol

Editorial responsibility: Thomas Minello,

Galveston, Texas, USA
Conserv 20:111-122

Sun D, Walsh D (1998) Review of studies on environmental impacts of recreation and tourism in Australia. J Environ Manage 53:323-338

> Thierfelder C, Amézquita E, Stahr K (2005) Effects of intensifying organic manuring and tillage practices on penetration resistance and infiltration rate. Soil Tillage Res 82: 211-226

Zar JH (1996) Biostatistical analysis. Prentice-Hall, Upper Saddle River, NJ

Submitted: May 23, 2008; Accepted: August 11, 2008

Proofs received from author(s): January 14, 2009 